\title{
Does ganciclovir exert retinal toxicity after multiple continuous intravitreal injections?
}

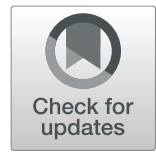

Feng $\mathrm{Hu}^{1,2,3}, \mathrm{Ya} \mathrm{Ma}^{1,2,3}$ and Xiaoyan Peng ${ }^{1,2,3^{*}}$

\begin{abstract}
Background: The objective of this study is to report a case of acute retinal necrosis in which abnormalities in visual function did not correspond to retinal anatomical outcomes.

Case presentation: A 39-year-old female diagnosed with acute retinal necrosis underwent repeated (nine rounds) intravitreal ganciclovir injection $(3 \mathrm{mg} / 0.1 \mathrm{ml}$ ) into the left eye, one injection every 2 weeks. During the therapy, the patient noticed her visual acuity declining gradually. The best corrected visual acuity in the left eye was 20/33. The visual field showed massive visual damage. There was no posterior necrotizing involvement, no macular edema or exudation, and only slight abnormity of the interdigitation zone in the fovea area was visible on OCT. Angio-OCT revealed normal capillary density of three retinal capillary and choriocapillaris layers. The visually evoked potential was normal. The photopic single-flash response showed a declined amplitude of a-wave and b-wave. The amplitudes of photopic $30 \mathrm{~Hz}$ flicker were decreased. Multifocal electroretinography revealed macular dysfunction.
\end{abstract}

Conclusion: Ganciclovir-associated photoreceptor damage may induce abnormalities in retinal function in response to multiple continuous intravitreal ganciclovir injections at a relatively high dosage $(3 \mathrm{mg} / 0.1 \mathrm{ml})$.

Keywords: Retinal toxicity, Ganciclovir, Intravitreal injection, Acute retinal necrosis, Viral uveitis, Visual field

\section{Background}

Acute retinal necrosis (ARN) was first described in 1971 by Urayama and colleagues as a syndrome of acute panuveitis with retinal periarteritis progressing to necrotizing retinitis and retinal detachment [1]. Ganciclovir is an antiviral drug developed by Kelvin K Ogilvie in 1982 to treat herpesvirus [1]. Most of the known side effects of intravitreal ganciclovir are related to procedure rather than the drug itself. These include retinal detachment, vitreous hemorrhage, endophthalmitis, subconjunctival hemorrhage, and cataracts [2]. Retinal toxicity was reported to occur in response to high-dose

\footnotetext{
*Correspondence: drpengxy@163.com

'Beijing Institute of Ophthalmology, 17 Hougou Lane, Chongnei Street, Beijing 100005, People's Republic of China

${ }^{2}$ Beijing Tongren Eye Center, Beijing Tongren Hospital, Capital Medical University, 17 Hougou Lane, Chongnei Street, Beijing 100005, People's Republic of China

Full list of author information is available at the end of the article
}

intravitreal ganciclovir $(40 \mathrm{mg} / 0.1 \mathrm{ml}$ and $4 \mathrm{mg} / 0.04$ $\mathrm{ml}$ ) injection, and patients developed permanent retinal damage and visual loss developed [3, 4]. We report a case of acute retinal necrosis in which the retinal structure appeared relatively normal after repeated doses of intravitreal ganciclovir, but there were abnormalities in visual function, including visual field damage, abnormal electroretinography, and multifocal electroretinography.

\section{Case presentation}

A 39-year-old female came to our clinic complaining of gradual loss of visual in the left eye for 5 months. She had been diagnosed with acute retinal necrosis in the right eye, and wide-field photograph of the right eye showed patchy and diffusive retinal necrotic lesions (Fig. 1). Pars plana vitrectomy was performed due to retinal detachment of the right eye 5 months earlier. The visual acuity in the left eye at

(c) The Author(s). 2021 Open Access This article is licensed under a Creative Commons Attribution 4.0 International License, which permits use, sharing, adaptation, distribution and reproduction in any medium or format, as long as you give appropriate credit to the original author(s) and the source, provide a link to the Creative Commons licence, and indicate if changes were made. The images or other third party material in this article are included in the article's Creative Commons licence, unless indicated otherwise in a credit line to the material. If material is not included in the article's Creative Commons licence and your intended use is not permitted by statutory regulation or exceeds the permitted use, you will need to obtain permission directly from the copyright holder. To view a copy of this licence, visit http://creativecommons.org/licenses/by/4.0/. The Creative Commons Public Domain Dedication waiver (http://creativecommons.org/publicdomain/zero/1.0/) applies to the data made available in this article, unless otherwise stated in a credit line to the data. 


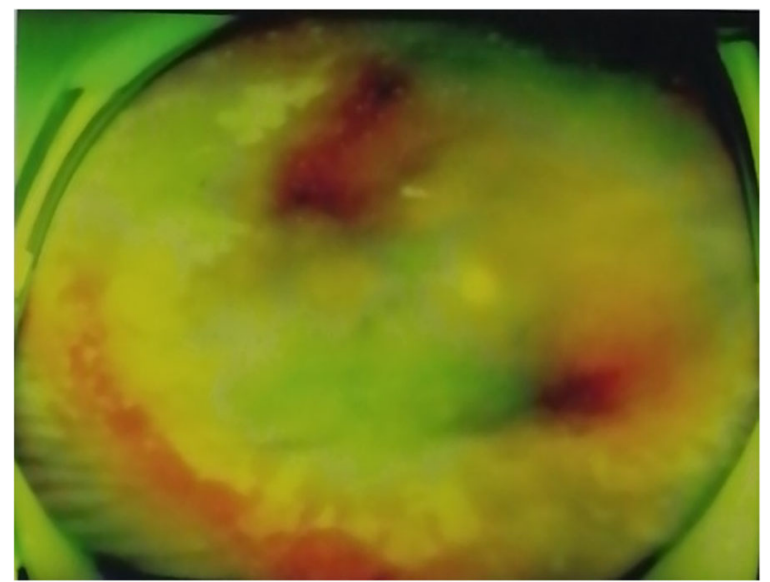

Fig. 1 Wide-field photograph of the right eye at initial presentation (five months ago). Wide-field photograph of the right eye showed patchy retinal necrotic lesions in superior and inferior peripheral retina, and diffusive retinal necrotic lesions in the temporal peripheral retina

the time of initial presentation was 20/20. In the meantime, she noticed floaters in her left eye. Superior retinal necrosis had been detected and it was recorded in her previous medical chart. The aqueous fluid from the left eye was positive for herpes zoster virus (VZV). She received repeated (nine rounds) intravitreal ganciclovir injection $(3 \mathrm{mg} / 0.1 \mathrm{ml})$ into her left eye, one injection every 2 weeks, and systemic antiviral therapy for 5 months. The patient noticed a decrease in the visual acuity of the left eye and was referred to our clinic.

When the patient came to our clinic, her best corrected visual acuity was 20/400 OS, 20/33 OS. The intraocular pressure was within the normal range in both eyes. There was no inflammation in the anterior chamber, and the lens was normal in the left eye. There was no posterior necrotizing involvement and no macular edema or exudation in the left eye. Indirect ophthalmoscope examination revealed pigmentary change in the superior peripheral retina of the left eye. Slight abnormality of the interdigitation zone in the fovea area of the left eye was detected on OCT. Angio-OCT revealed normal capillary density of superficial retinal capillary, deep retinal capillary, outer retina, and choriocapillaris layers in the left eye (Fig. 2). The Humphrey visual field (central 24-2 threshold test) showed massive visual field damage in the left eye. The amplitude and implicit times of pattern visually evoked potential (VEP) and flash VEP were within the normal range in the left eye. The amplitudes of dark-adapted flash electroretinography (ERG) were slightly low in the left eye. Photopic single-flash response showed decreased

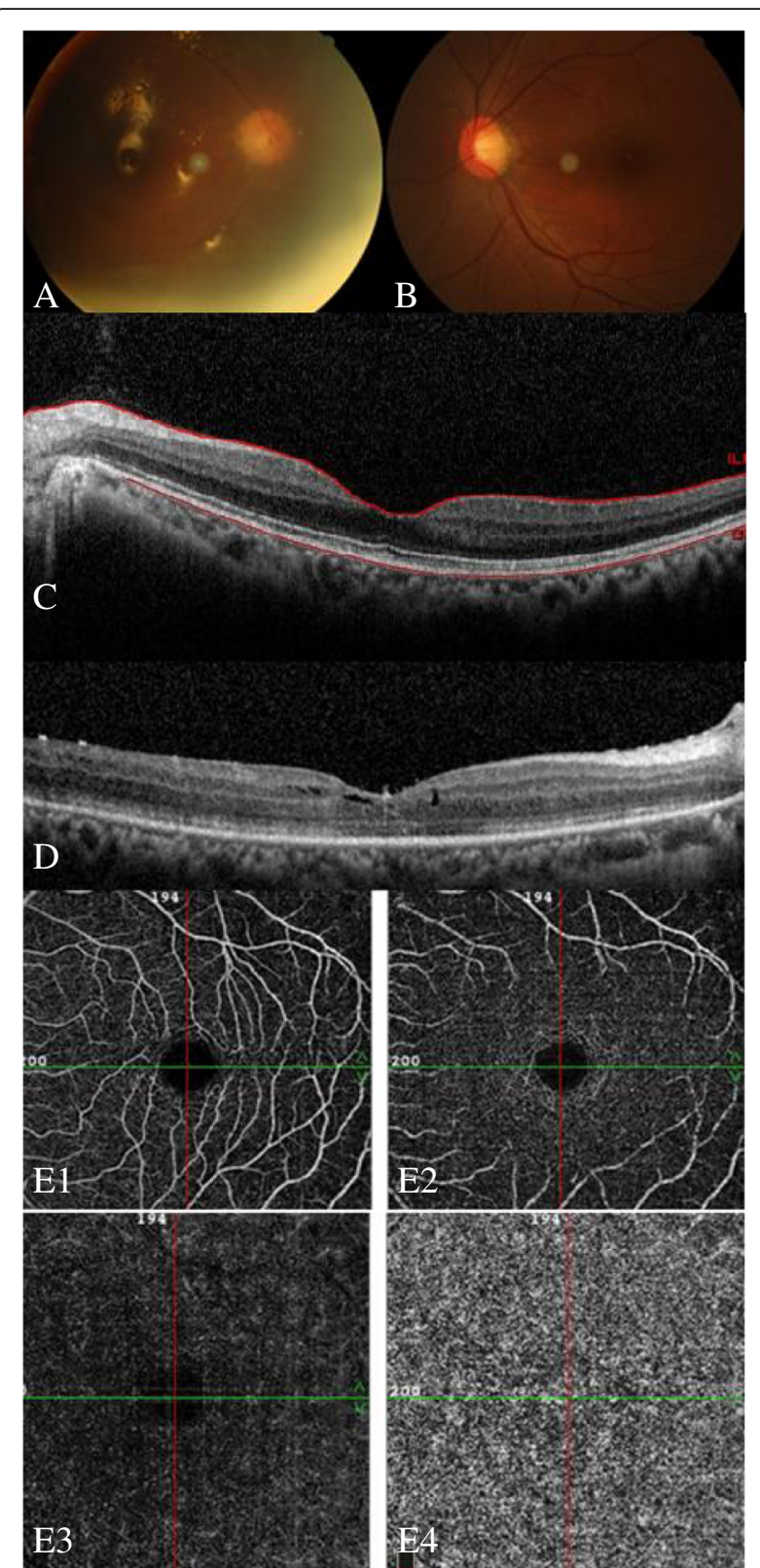

Fig. 2 Multi-images of a 39-year-old female acute retinal necrosis patient. A The right fundus showed silicone oil tamponade. B The left fundus showed no necrosis, no exudation, and no edema in the macular area, and the optic disc appeared normal. C Optical coherence tomography of left eye showed slight abnormality of the interdigitation zone in fovea area. D Optical coherence tomography of the right eye showed macular edema and rupture of the interdigitation zone. E1-4 Superficial retinal capillary, deep retinal capillary, outer retina, and choriocapillaris layers of angio-OCT for the left eye

amplitude of a-wave and b-wave in the left eye. The amplitudes of photopic $30-\mathrm{Hz}$ flicker were decreased in the left eye. Trace arrays showed subnormal multifocal electroretinography (mERG) with decreased amplitudes for the left eye. The three- 
dimensional topography map showed a blunted foveal peak (Fig. 3).

\section{Discussion and conclusions}

We here report a case of acute retinal necrosis in which the retinal structure appeared relatively normal after repeated doses of intravitreal ganciclovir, but the visual function abnormalities were remarkable. The posterior segment showed not involvement with retinal necrosis, and there was no macular edema or exudation. Flash and pattern VEP appeared normal for the left eye, so optic nerve involvement of the left eye was excluded. The anatomical outcome was good, with only slight abnormality of interdigitation zone in fovea area in the left eye on OCT. The abnormal ERG revealed retinal dysfunction. The mERG revealed macular dysfunction. What is unusual in the present case is that she accepted nine rounds of continuous intravitreal ganciclovir injections at a relatively high dosage $(3 \mathrm{mg} / 0.1 \mathrm{ml})$.

Viral infection and inflammation in ARN induce damage to retinal structures and corresponding visual function abnormities. Photoreceptor damage in ARN was here confirmed by OCT observations: hyper-reflective vertical strips within the outer nuclear layer, retinal disruption, and interruption of photoreceptors [5]. Abnormal ERG exams indicating photoreceptor and bipolar cell damage may be associated with ARN induced retinal function damage. What is special in the present case is that abnormal ERG and visual field confirmed abnormal retinal function. In the meantime, the retinal anatomical outcome was relatively good and there were no detectable ARN-induced structural changes.

Intravitreal ganciclovir injection has been used to treat ARN and cytomegalovirus retinitis (CMVR). The

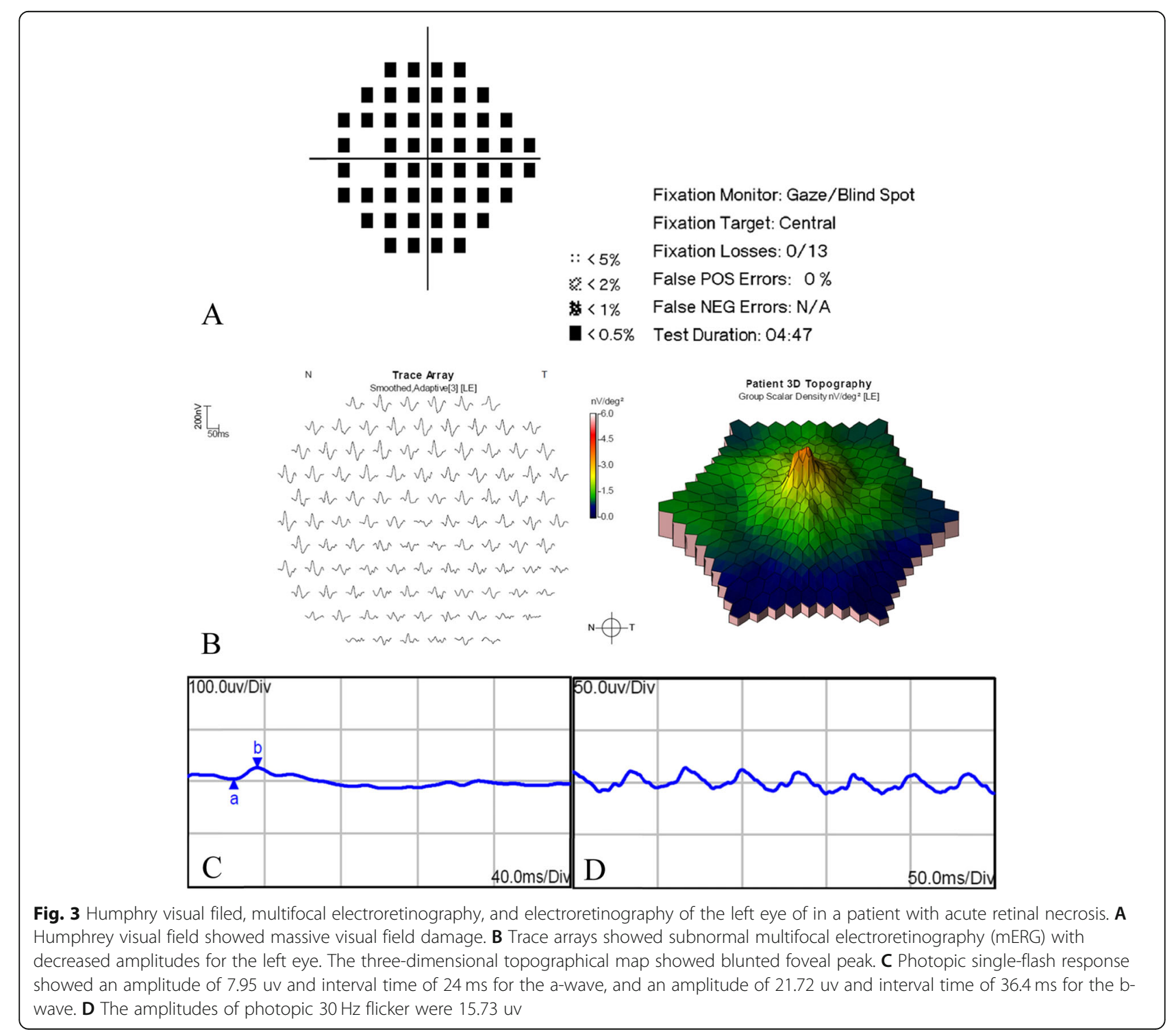


recommended dosage of intravitreal ganciclovir used to treat herpetic uveitis is $200-400 \mu \mathrm{g} / 0.1 \mathrm{ml}$. Intravitreal ganciclovir injection at doses of $1 \mathrm{mg}, 2 \mathrm{mg}, 3 \mathrm{mg}$ and $5 \mathrm{mg}$ has also been used to treat ARN and CMVR [2, 6-8]. In one prospective interventional case series, intravitreal ganciclovir injection of $5 \mathrm{mg} /$ $0.1 \mathrm{ml}$ once a week was used to treat active CMVR, and no retinal toxicity was observed [2]. The dosage of intravitreal ganciclovir injection capable of causing retinal toxicity is still unclear. Intravitreal ganciclovir (at doses of $40 \mathrm{mg} / 0.1 \mathrm{ml}$, and $4 \mathrm{mg} / 0.04 \mathrm{ml}$ ) has been reported to show retinal toxicity in previous works, with sudden formation of precipitated crystalline material after the intravitreal injection accompanied by high intraocular pressure. The decrease in visual acuity occurred immediately after intravitreal injection [3, 4]. Retinal edema, cherry spot, and delayed arm to retina time supported the conclusion that retinal artery occlusion occurs in the acute retinal toxicity of ganciclovir [4]. The alkaline nature of the solution, osmotic damage, and precipitation of ganciclovir within the retina may cause direct or indirect cellular injury and act in etiology of retinal toxic reaction produced by the highly concentrated ganciclovir [3].

In the present case, there was no sudden decline in visual acuity, and the IOP remained within normal range. The retina and optic disc appeared normal. In this way, there was no evidence supporting a diagnosis of acute retinal toxicity of ganciclovir, as in previous examinations of the present patient. In addition to acute intraocular inflammation and retinal arterial occlusion, photoreceptor damage was confirmed in ganciclovir associated retinal toxicity with loosely arranged swollen photoreceptors, and decreased photoreceptor outer segments upon transmission electron microscope examination [9]. A decrease in a-wave amplitude on ERG indicated photoreceptor dysfunction in the present case, which may be associated with ganciclovir toxicity, but it differed from previous reports of acute retinal toxicity. The limitation of this case is that there was no continuous imaging and functional exams during intravitreal ganciclovir injections.

In conclusion, after excluding ARN associated direct structural damage and acute retinal toxicity of high concentrations of ganciclovir, ganciclovir-associated photoreceptor damage was found capable of inducing abnormalities in retinal function after multiple continuous intravitreal ganciclovir injections at a relatively high dosage $(3 \mathrm{mg} / 0.1 \mathrm{ml})$, which merits further investigation.

\section{Abbreviations}

ARN: Acute retinal necrosis; VZV: Herpes zoster virus; OCT: Optical coherence tomography; VEP: Visually evoked potential; ERG: Electroretinography; CMVR: Cytomegalovirus retinitis

\section{Acknowledgements}

We acknowledge the contribution and support Beijing Institute of Ophthalmology for providing imaging of the patient.

\section{Authors' contributions}

Writing, draft preparation: F H. Conceptualization: Y M. Review and editing: $X$ $P$. The authors read and approved the final manuscript.

\section{Funding}

Thanks to support by The Capital Health Research and Development of Special (No.SF-2018-2-1081), Capital Medical University Affiliated Beijing Tongren Hospital Key Medical Development Plan (trzdyxzy201801). The funding organization had no role in the design or conduct of this research.

Availability of data and materials

All data of this case report is included in this published article.

\section{Declarations}

\section{Ethics approval and consent to participate}

The submission of this case report for publication was notified by the IRB (Beijing Tongren Hospital, Beijing, China) and the need for ethics approval was waived.

\section{Consent for publication}

Written informed consent for publication was obtained from the patient.

\section{Competing interests}

The author(s) have no proprietary or commercial interest in any drugs and equipment used in this article.

\section{Author details}

${ }^{1}$ Beijing Institute of Ophthalmology, 17 Hougou Lane, Chongnei Street, Beijing 100005, People's Republic of China. 'Beijing Tongren Eye Center, Beijing Tongren Hospital, Capital Medical University, 17 Hougou Lane, Chongnei Street, Beijing 100005, People's Republic of China. ${ }^{3}$ Beijing Ophthalmology and Visual Science Key Laboratory, 17 Hougou Lane, Chongnei Street, Beijing 100005, People's Republic of China.

Received: 3 September 2020 Accepted: 28 June 2021

Published online: 12 July 2021

\section{References}

1. Schoenberger SD, Kim SJ, Thorne JE, Mruthyunjaya P, Yeh S, Bakri SJ, et al. Diagnosis and treatment of acute retinal necrosis: a report by the American Academy of ophthalmology. Ophthalmology. 2017;124(3):382-92. https:// doi.org/10.1016/j.ophtha.2016.11.007.

2. Arevalo JF, Garcia RA, Mendoza AJ. High-dose (5000-microg) intravitreal ganciclovir combined with highly active antiretroviral therapy for cytomegalovirus retinitis in HIV-infected patients in Venezuela. Eur J Ophthalmol. 2005;15(5):610-8. https://doi.org/10.1177/112067210501 500512

3. Saran BR, Maguire AM. Retinal toxicity of high dose intravitreal ganciclovir. Retina. 1994;14(3):248-52. https://doi.org/10.1097/00006982-1 99414030-00010.

4. Choopong P, Tesavibul N, Rodanant N. Crystallization after intravitreal ganciclovir injection. Clin Ophthalmol. 2010;4:709-11. https://doi.org/10.214 7/opth.s10949.

5. Invernizzi A, Agarwal AK, Ravera V, Mapelli C, Riva A, Staurenghi G, et al. Comparing optical coherence tomography findings in different aetiologies of infectious necrotising retinitis. Br J Ophthalmol. 2018;102(4):433-7. https://doi.org/10.1136/bjophthalmol-2017-310210.

6. Teoh SC, Ou X, Lim TH. Intravitreal ganciclovir maintenance injection for cytomegalovirus retinitis: efficacy of a low-volume, intermediate-dose regimen. Ophthalmology. 2012;119(3):588-95. https://doi.org/10.1016/j. ophtha.2011.09.004.

7. Velez G, Roy CE, Whitcup SM, Chan CC, Robinson MR. High-dose intravitreal ganciclovir and foscarnet for cytomegalovirus retinitis. Am J Ophthalmol. 2001;131(3):396-7. https://doi.org/10.1016/S0002-9394 (00)00785-6. 
8. Choopong P, Vivittaworn K, Konlakij D, Thoongsuwan S, Pituksung A, Tesavibul N. Treatment outcomes of reduced-dose intravitreal ganciclovir for cytomegalovirus retinitis. BMC Infect Dis. 2016;16(1):164. https://doi.org/1 0.1186/s12879-016-1490-6.

9. Sun BJ, Peng RM, Lu Q, et al. Retinal and corneal toxicity and pharmacokinetic analysis of intraocular injection of ganciclovir in rabbit eyes. J Ophthalmol. 2019;2019:3054758.

\section{Publisher's Note}

Springer Nature remains neutral with regard to jurisdictional claims in published maps and institutional affiliations.

Ready to submit your research? Choose BMC and benefit from:

- fast, convenient online submission

- thorough peer review by experienced researchers in your field

- rapid publication on acceptance

- support for research data, including large and complex data types

- gold Open Access which fosters wider collaboration and increased citations

- maximum visibility for your research: over $100 \mathrm{M}$ website views per year

At $\mathrm{BMC}$, research is always in progress. 